\title{
Fluorometric Determination of Aromatic Aldehydes with 1,4-Dimethyl-3-carbamoylpyridinium Chloride
}

\author{
Akira Sano, Makoto Ogawa and Shoji Takitani \\ Faculty of Pharmaceutical Sciences, Science University of Tokyo, \\ Ichigaya-funagawara-machi, Shinjuku, Tokyo 162
}

\begin{abstract}
1,4-Dimethyl-3-carbamoylpyridinium chloride (DCP.Cl) has been synthesized as a new fluorogenic reagent for aromatic aldehydes. Aldehydes gave a green fluorescence $\left(\lambda_{\mathrm{ex}} 420-439 \mathrm{~nm}\right.$ and $\lambda_{\mathrm{em}} 504-519 \mathrm{~nm}$ ) after reaction with $\mathrm{DCP} \cdot \mathrm{Cl}$ at $37^{\circ} \mathrm{C}$ for $50 \mathrm{~min}$ in the presence of alkali and sodium sulfite. The method is simple and sensitive for aromatic aldehydes except for those having hydroxy or dimethylamino group. Aliphatic and arylaliphatic aldehydes and substances other than aldehydes showed no or weak fluorescence. By the proposed method, benzaldehyde, furfural and 4-methoxybenzaldehyde could be determined in the ranges $0.06-3 \mathrm{nmol} / \mathrm{ml}, 0.08$ $3 \mathrm{nmol} / \mathrm{ml}$ and $0.3-6 \mathrm{nmol} / \mathrm{ml}$, respectively, with relative standard deviations of $0.5-2.5 \%$.
\end{abstract}

Keywords Aromatic aldehyde, 1,4-dimethyl-3-carbamoylpyridinium chloride, fluorometry, benzaldehyde

Some aromatic aldehydes are often found in foodstuffs ${ }^{1}$ and environmental materials such as waste by-products of manufactures. ${ }^{2}$ In biological fluids there are many substances such as vanillylmandelic acid $^{3}$ and $p$-hydroxyphenylpyruvic acid 4 which can be easily converted to aromatic aldehydes. Enzymes such as monoamine oxidase ${ }^{5}$ have been assayed by measuring aromatic aldehydes formed from substrates. Therefore, a sensitive and selective method for determination of aromatic aldehydes is needed. Several fluorogenic reagents such as 2-aminobenzenethiol $(\mathrm{ABT})^{6}, 1,2$-diaminonaphthalene (DAN) ${ }^{7}, 2,2^{\prime}-$ dithiobis(1-aminonaphthalene) (DTAN) ${ }^{8}$ and 4,5-dimethoxy-1,2-diaminobenzene (DDB) 9 have been proposed for selective determination of aromatic aldehydes at sub-nanomole levels. These reagents react with aldehydes in acidic medium to produce fluorophore; but some additional treatments are required for the fluorescence development; e.g., solvent extraction ${ }^{6}$ and addition of alkali and/or 2-mercaptoethanol. ${ }^{7-9}$ These methods also have some defects. The reaction condition in ABT method is drastic. DAN should be handled with extreme care because of its carcinogenicity. DTAN is itself fluorescent. DDB solution

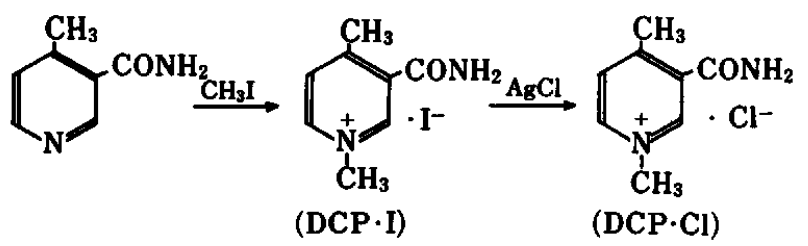

Fig. 1 Synthesis of DCP.I and DCP.Cl. must be used within $3 \mathrm{~h}$ after the preparation because of its low stability. Therefore we searched for a fluorogenic reaction suitable for the determination of aromatic aldehydes.

1,4-Dimethyl-3-carbamoylpyridinium chloride (DCP. Cl) and iodide (DCP.I) (Fig. 1) were designed and synthesized as a new fluorogenic reagent for our purpose from analogy with a fluorogenic reaction of $\alpha$-methylene carbonyl compounds with $\mathbf{N}^{1}$-methylnicotinamide $^{10,11}$ and related compounds. ${ }^{12}$ DCP halide molecules have three functional groups. These are considered to act as follows: 1) methyl group at N1 activates the reactivity of methyl group at $\mathrm{C} 4$ on pyridine ring ${ }^{13}$; 2) methyl group at $\mathrm{C} 4$ conjugates with aldehyde group selectively ${ }^{13}$; and 3 ) carbamoyl group at C3 makes it possible to transform the intermediate to fluorophore. The present work aimed to establish a sensitive and selective fluorometric method for determining aromatic aldehydes by using the proposed reagents.

\section{Experimental}

\section{Chemicals and apparatus}

Aldehydes used were obtained from Kanto Chemical Co., Tokyo Kasei Co. and Nakarai Chemicals Co. Stock standard solutions of aldehydes were prepared at $1 \mathrm{mM}$ concentration in water whenever possible or in ethanol. Diluted solutions were prepared by using water. Water used was purified on a Milli RO-Milli Q system (Millipore Ltd.). All chemicals used were of analytical-reagent grade. 
${ }^{1} \mathrm{H}-\mathrm{NMR}$ spectra were recorded on a JEOL JNM FX-100 spectrometer operated at $100 \mathrm{MHz}$ using tetramethylsilane as an internal standard (abbreviation: s, singlet; d, doublet). MS spectra were obtained with a Hitachi M-80 double-focusing mass spectrometer. A Hitachi F-3000 fluorescence spectrometer was used with a $1-\mathrm{cm}$ quartz cell at room temperature. The spectral bandwidths were $5 \mathrm{~nm}$ for both excitation and emission. All fluorescence excitation and emission spectra were uncorrected.

\section{Synthesis of $D C P \cdot I$ and $D C P \cdot C l$}

DCP.I was prepared from 4-methylnicotinamide ${ }^{14}$ $(12 \mathrm{~g})$ by the method of Girgis-Takla et al. ${ }^{11}$ for the preparation of $\mathrm{N}^{1}$-methylnicotinamide iodide. The product obtained was washed with small amounts of ethanol and diethyl ether. DCP.I was used without further purification (white powder, yield 77\%): $\mathrm{mp}$ 202-204 ${ }^{\circ} \mathrm{C}$ (dec., uncorrected); ${ }^{1} \mathrm{H}-\mathrm{NMR}$ (in $\mathrm{CF}_{3} \mathrm{COOD}$ ) $\delta 2.28$ (3H, s), $4.49(3 \mathrm{H}, \mathrm{s}), 7.96(1 \mathrm{H}, \mathrm{d}, J=6.3 \mathrm{~Hz})$, $8.62(1 \mathrm{H}, \mathrm{d}, J=6.3 \mathrm{~Hz}), 8.96(1 \mathrm{H}, \mathrm{s}) ; \mathrm{MS} m / z: 150$ ([M-HI $]^{+}$); Anal. Calcd for $\mathrm{C}_{8} \mathrm{H}_{11} \mathrm{~N}_{2} \mathrm{OI}: 34.55 \% \mathrm{C}$, $3.99 \% \mathrm{H}, 10.07 \% \mathrm{~N}, \mathbf{4 5 . 6 3 \%} \mathrm{I}$; found: $34.60 \% \mathrm{C}, 4.05 \%$ $\mathrm{H}, 9.91 \% \mathrm{~N}, \mathbf{4 5 . 7 4 \%} \mathrm{I}$.

DCP.Cl was prepared from DCP.I by the method of Karrer et al. ${ }^{15}$ for the preparation of $\mathrm{N}^{1}$-methylnicotinamide chloride. To a solution of DCP.I $(10 \mathrm{~g})$ in water $(50 \mathrm{ml})$ was added silver chloride $(15.4 \mathrm{~g})$; the mixture was stirred for $2 \mathrm{~h}$ at room temperature. After removing the precipitate, the aqueous solution was evaporated to dryness under reduced pressure. DCP. $\mathrm{Cl}$ obtained was used without further purification (white powder, yield 95\%): mp $209-211^{\circ} \mathrm{C}$ (dec., uncorrected); ${ }^{1} \mathrm{H}-\mathrm{NMR}$ (in $\left.\mathrm{CF}_{3} \mathrm{COOD}\right) \delta 2.86(3 \mathrm{H}, \mathrm{s})$, $4.48(3 \mathrm{H}, \mathrm{s}), 7.98(1 \mathrm{H}, \mathrm{d}, J=6.3 \mathrm{~Hz}), 8.63(1 \mathrm{H}, \mathrm{d}$, $J=6.3 \mathrm{~Hz}), 8.92(1 \mathrm{H}, \mathrm{s}) ; \mathrm{MS} \mathrm{m} / \mathrm{z}: 150\left([\mathrm{M}-\mathrm{HCl}]^{+}\right)$; Anal. Calcd for $\mathrm{C}_{8} \mathrm{H}_{11} \mathrm{~N}_{2} \mathrm{OCl}: 51.48 \% \mathrm{C}, 5.94 \% \mathrm{H}$, $15.01 \% \mathrm{~N}, 19.00 \% \mathrm{Cl}$; found: $50.63 \% \mathrm{C}, 5.95 \% \mathrm{H}$, $14.93 \% \mathrm{~N}, 18.66 \% \mathrm{Cl}$.

\section{Recommended procedure}

To $1 \mathrm{ml}$ of sample solution in a $1.5-\mathrm{ml}$ glassstoppered test tube are added $50 \mu 1$ of $0.4 \mathrm{M} \mathrm{DCP} \cdot \mathrm{Cl}$ in water and $100 \mu$ l of $1.5 \mathrm{M}$ aqueous sodium hydroxide solution containing $20 \mathrm{mM}$ sodium sulfite. The mixture is then incubated for $50 \mathrm{~min}$ at $37^{\circ} \mathrm{C}$. After cooling to room temperature, the fluorescence intensity was measured with excitation at $436 \mathrm{~nm}$ and emission at $506 \mathrm{~nm}$.

\section{Results and Discussion}

\section{Reaction conditions}

In preliminary experiments using formaldehyde, benzaldehyde, acetophenone, benzoic acid and benzyl alcohol as test compounds, it was found that only benzaldehyde gave an intense green fluorescence under $365 \mathrm{~nm}$ UV light after reaction with DCP.Cl or DCP.I in the presence of alkali. Formaldehyde gave a weak fluorescence. Other substances and a reagent blank gave a negligible faint blue fluorescence.

When 1,2-dimethyl-3-carbamoylpyridinium iodide, which was prepared from 2-methylnicotinamide ${ }^{16}$ and methyl iodide was used as a reagent, benzaldehyde showed no fluorescence. Benzaldehyde gave also no fluorescence by reaction with 1,4-dimethylpyridinium iodide. ${ }^{17}$ The presence of methyl group at $\mathrm{C} 4$ and carbamoyl group at C3 on the pyridine ring is considered essential for the fluorescence development of benzaldehyde, though details on the reaction product are not clear.

Thus DCP halides seemed applicable to the determination of aromatic aldehydes with good sensitivity and selectivity. Reaction conditions for determining them were examined by taking benzaldehyde as a standard.

In the reaction of benzaldehyde, the fluorescence intensity obtained with $\mathrm{DCP} \cdot \mathrm{Cl}$ was about twice as much as that obtained with DCP.I. This phenomenon can probably be attributed to the quenching effect of iodide ion, because addition of iodide ion (sodium iodide) corresponding to DCP.I concentration to the final reaction mixture obtained from benzaldehyde with DCP.Cl caused a similar decrement of the fluorescence intensity. Thus DCP. $\mathrm{Cl}$ was used in the present study.

Benzaldehyde reacted with $\mathrm{DCP} \cdot \mathrm{Cl}$ in dilute alkaline solution but not in neutral and acidic solutions. The reaction was also observed to occur in the presence of organic amines such as piperidine and diethylamine,

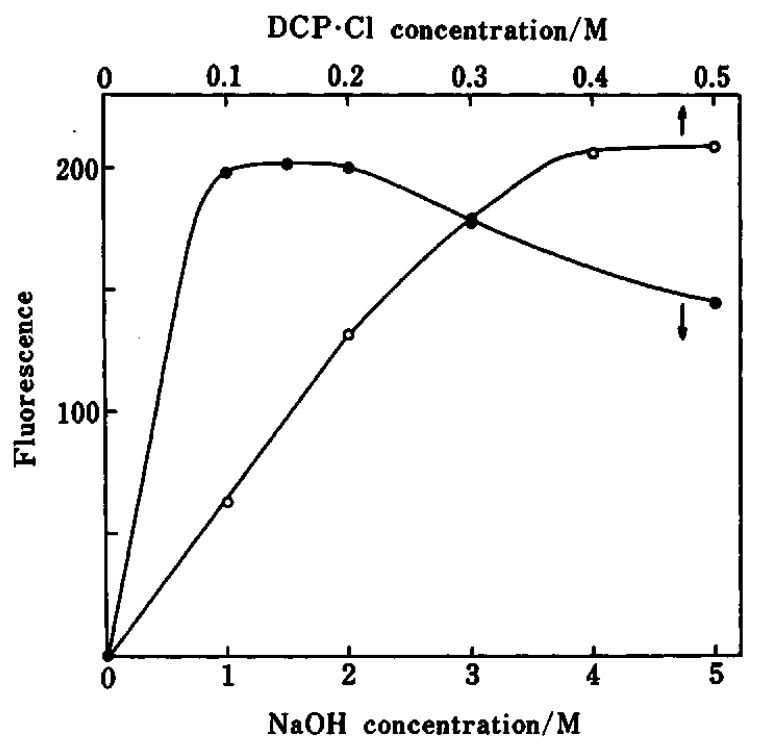

Fig. 2 Effects of sodium hydroxide and DCP.Cl concentrations on the fluorescence reaction of benzaldehyde: $(O)$ sodium hydroxide, (O) DCP.Cl. Benzaldehyde (2 nmol/ $\mathrm{ml}$ ) was treated by the recommended procedure, except that 1.5 $\mathrm{M}$ sodium hydroxide or $0.4 \mathrm{M} \mathrm{DCP} \cdot \mathrm{Cl}$ was replaced by varying concentrations of the reagents. 
but these amines gave a higher blank fluorescence intensity. Thus sodium hydroxide was selected. Figure 2 shows the effects of sodium hydroxide and $\mathrm{DCP} \cdot \mathrm{Cl}$ concentrations. Constant fluorescence intensities were obtained over the concentration ranges from 1 to $2 \mathrm{M}$ for the former and 0.4 to $0.5 \mathrm{M}$ for the latter. Therefore the use of $1.5 \mathrm{M}$ sodium hydroxide and 0.4 M DCP.Cl was recommended.

Reducing agents such as sodium sulfite, sodium bisulfite and sodium pyrosulfite decreased the blank fluorescence intensity. The potency of these reagents for this effect was almost the same; so sodium sulfite was arbitrarily used. The blank fluorescence intensity decreased with an increase in sodium sulfite concentration, but the fluorescence intensity of benzaldehyde also decreased at more than $50 \mathrm{mM}$ concentration; so $20 \mathrm{mM}$ sodium sulfite was used. The blank fluorescence intensity under this condition was about $50 \%$ of the value obtained in its absence. Sodium hydroxide and sodium sulfite could be used conveniently in a mixture.

Next, the effects of reaction temperature and time were studied. The results obtained are shown in Fig. 3. Although the reaction of benzaldehyde occurred even at room temperature, the reaction was accelerated with the increase of temperature. However above $50^{\circ} \mathrm{C}$, the fluorescence decay was also accelerated, and higher temperatures gave higher blank fluorescence intensities. At $37^{\circ} \mathrm{C}$, the fluorescence intensity reached a constant value after $40-60 \mathrm{~min}$. Thus the reaction at $37^{\circ} \mathrm{C}$ for $50 \mathrm{~min}$ was selected.

The effect of $\mathrm{pH}$ on the fluorescence properties of the reaction mixture resulting from benzaldehyde was studied. When varying $\mathrm{pH}$ values of buffers were

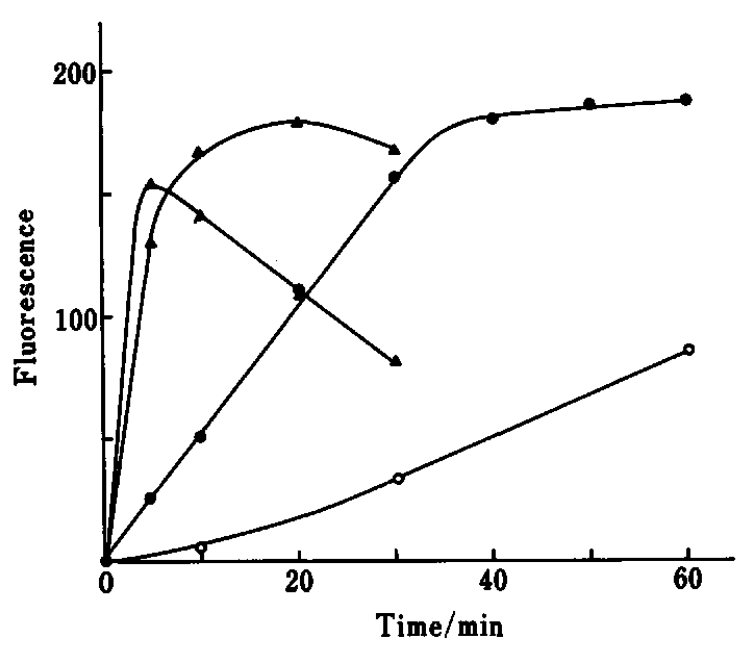

Fig. 3 Effects of reaction temperature and time on the fluorescence reaction of benzaldehyde: $(O)$ room temperature, $(\Theta) 37^{\circ} \mathrm{C},(\Delta) 50^{\circ} \mathrm{C},(\Delta) 70^{\circ} \mathrm{C}$. Benzaldehyde $(2$ $\mathrm{nmol} / \mathrm{ml}$ ) was incubated at various temperatures and times. Other conditions are the same as in the recommended procedure. added to the reaction mixture, three types of fluorescence characteristics were observed. Fluorescence maxima were found at $\lambda_{\mathrm{ex}} 390 \mathrm{~nm}$ and $\lambda_{\mathrm{em}} 460 \mathrm{~nm}$ in strongly acidic media (below pH 0.7), at $\lambda_{\mathrm{ex}} 390 \mathrm{~nm}$ and $\lambda_{\text {em }} 506 \mathrm{~nm}$ at around pH 2-4, and at $\lambda_{\text {ex }} 436 \mathrm{~nm}$ and $\lambda_{\mathrm{em}} 506 \mathrm{~nm}$ in alkaline region above $\mathrm{pH} 7$. To select the best analytical condition, the fluorescence properties of the reaction mixture itself (recommended conditions) were compared with those obtained by using various inorganic and organic acids (5 M solution, $500 \mu \mathrm{l}$ ) in place of buffers for convenience. In general, higher fluorescence intensity and more stability were obtained by addition of acids. But the optimal condition was determined as the alkaline condition because it gave the highest ratio of test to blank in the fluorescence; the alkaline condition was simpler as well. The fluorescence was stable for $30 \mathrm{~min}$ at room temperature. If desired, the use of acetic acid was able to prevent the fluorescence decrement over several hours. The determination range of benzaldehyde by using acetic acid ( $\lambda_{\text {ex }} 390 \mathrm{~nm}$ and $\lambda_{\mathrm{em}} 506 \mathrm{~nm}$ ) was comparable to that of the recommended condition.

\section{Fhuorescence from aldehydes and other substances}

The fluorescence characteristics and intensities of 27 aldehydes obtained by the recommended procedure are summarized in Table 1. All aldehydes listed had similar spectra as to the maximal wavelengths for fluorescence excitation and emission, but with pronounced differences in relative fluorescence intensity. In general, the proposed method is sensitive for aromatic aldehydes but not for aliphatic and arylaliphatic aldehydes. Although benzaldehyde derivatives having a dimethylamino or hydroxy group such as 4dimethylaminobenzaldehyde, 2-, 3- and 4-hydroxybenzaldehydes, 3-hydroxy-4-methoxybenzaldehyde and 4-hydroxy-3-methoxybenzaldehyde gave no fluorescence at a concentration of $1 \mu \mathrm{mol} / \mathrm{ml}$, it was found that addition of methanesulfonyl chloride was effective for the fluorescence development of benzaldehydes having hydroxy group. When the reactions of these aldehydes were performed in the presence of $3 \mu$ l of methanesulfonyl chloride, the fluorescence intensities obtained were $3.6-58 \%$ of the value for benzaldehyde obtained by the recommended procedure (Table 2).

Benzoic acid, benzyl alcohol, acetophenone, phenol, 11 different amino acids (asparagine, aspartic acid, cysteine, histidine, leucine, lysine, methionine, phenylalanine, proline, threonine and tryptophan), glutathione, pyruvic acid, oxalacetic acid, $\alpha$-ketoglutaric acid and saccharose showed no fluorescence at a concentration of $1 \mu \mathrm{mol} / \mathrm{ml}$. Glucose and maltose gave a fluorescence; the intensities of $0.3 \mu \mathrm{mol} / \mathrm{ml}$ solution were only twice the blank value.

\section{Calibration curves}

Calibration curves were constructed for benzaldehyde, 4-methoxybenzaldehyde and furfural by the recommended procedure. The fluorescence intensities 
Table 1 Relative fluorescence intensities and maximal wavelengths for some aldehydes

\begin{tabular}{|c|c|c|c|}
\hline \multirow{2}{*}{ Aldehyde } & \multicolumn{2}{|c|}{$\lambda_{\max } / \mathrm{nm}$} & \multirow{2}{*}{$\mathbf{R F I}^{\mathbf{b}}$} \\
\hline & $\mathbf{E x}$ & $\overline{\mathbf{E m}}$ & \\
\hline Benzaldehyde & 436 & 506 & 100 \\
\hline 2-Chlorobenzaldehyde & 435 & 504 & 108 \\
\hline 3-Chlorobenzaldehyde & 437 & 505 & 105 \\
\hline 4-Chlorobenzaldehyde & 437 & 506 & 90 \\
\hline 2-Methylbenzaldehyde & 438 & 507 & 93 \\
\hline 3-Methylbenzaldehyde & 437 & 507 & 94 \\
\hline 4-Methylbenzaldehyde & 438 & 508 & 73 \\
\hline 2-Methoxybenzaldehyde & 437 & 506 & 78 \\
\hline 3-Methoxybenzaldehyde & 438 & 507 & 89 \\
\hline 4-Methoxybenzaldehyde & 438 & 509 & 20 \\
\hline o-Phthalaldehyde & 420 & 507 & 0.4 \\
\hline Terephthalaldehyde & 437 & 508 & 92 \\
\hline 2,6-Dichlorobenzaldehyde & 442 & 517 & 4.0 \\
\hline 2,3-Dimethoxybenzaldehyde & 438 & 509 & 26 \\
\hline 3,4-Dimethoxybenzaldehyde & 437 & 507 & 0.1 \\
\hline 1-Naphthaldehyde & 437 & 507 & 84 \\
\hline 2-Naphthaldehyde & 438 & 507 & 84 \\
\hline Pyridine-3-aldehyde & 437 & 504 & 106 \\
\hline Pyridine-4-aldehyde & 437 & 504 & 103 \\
\hline Furfural & 436 & 506 & 67 \\
\hline Phenylacetaldehyde & 437 & 510 & 1.2 \\
\hline trans-Cinnamaldehyde & 438 & 511 & 7.7 \\
\hline Formaldehyde & 439 & 519 & 0.1 \\
\hline Acetaldehyde & 435 & 510 & 0.4 \\
\hline Propionaldehyde & 437 & 510 & 0.5 \\
\hline Acrolein & 437 & 510 & 1.4 \\
\hline Crotonaldehyde & 437 & 510 & 2.0 \\
\hline
\end{tabular}

a. Aldehydes $(2-100 \mathrm{nmol} / \mathrm{ml})$ were treated by the recommended procedure.

b. Relative fluorescence intensity at maximal wavelengths; benzaldehyde is arbitrarily taken as 100 . Each value represents the mean of three runs.

Table 2 Relative fluorescence intensities and maximal wavelengths for benzaldehydes having hydroxy group

\begin{tabular}{|c|c|c|c|}
\hline \multirow{2}{*}{ Aldehyde^ } & \multicolumn{2}{|c|}{$\lambda_{\max } / \mathrm{nm}$} & \multirow{2}{*}{ RFI ${ }^{b}$} \\
\hline & $\overline{\mathbf{E x}}$ & $\overline{\mathbf{E m}}$ & \\
\hline 2-Hydroxybenzaldehyde & 431 & 502 & 3.6 \\
\hline 3-Hydroxybenzaldehyde & 435 & 505 & 58 \\
\hline 4-Hydroxybenzaldehyde & 438 & 507 & 43 \\
\hline 3-Hydroxy-4-methoxybenzaldehyde & 432 & 502 & 30 \\
\hline 4-Hydroxy-3-methoxybenzaldehyde & 438 & 507 & 28 \\
\hline
\end{tabular}

a. Aldehydes $(2 \mathrm{nmol} / \mathrm{ml})$ were treated by the recommended procedure in the presence of $3 \mu l$ of methanesulfonyl chloride.

b. Relative fluorescence intensity at maximal wavelength. The value obtained from benzaldehyde by the recommended procedure is arbitrarily taken as 100 . Each value represents the mean of three runs.

were proportional to the sample concentrations in the range $0.06-3 \mathrm{nmol} / \mathrm{ml}$ for benzaldehyde, $0.3-6$ $\mathrm{nmol} / \mathrm{ml}$ for 4-methoxybenzaldehyde and 0.08-3 $\mathrm{nmol} / \mathrm{ml}$ for furfural. The relative standard deviations $(n=9)$ were $1.4 \%$ (at $0.1 \mathrm{nmol} / \mathrm{ml}$ ) and $2.1 \%$ (at 2 $\mathrm{nmol} / \mathrm{ml}$ ) for benzaldehyde, $2.5 \%$ (at $0.5 \mathrm{nmol} / \mathrm{ml}$ ) and $0.6 \%$ (at $4 \mathrm{nmol} / \mathrm{ml}$ ) for 4-methoxybenzaldehyde and $2.1 \%$ (at $0.2 \mathrm{nmol} / \mathrm{ml}$ ) and $0.5 \%$ (at $2 \mathrm{nmol} / \mathrm{ml}$ ) for furfural. When the reaction was carried out in the presence of methanesulfonyl chloride $(3 \mu \mathrm{\mu l})$, 4hydroxybenzaldehyde could be determined in the range $0.25-10 \mathrm{nmol} / \mathrm{ml}$ with the relative standard deviations $(n=9)$ of $5.4 \%$ (at $0.5 \mathrm{nmol} / \mathrm{ml}$ ) and $3.8 \%$ (at 6 $\mathrm{nmol} / \mathrm{ml}$ ).

The DCP.Cl method is one of the best methods for determining aromatic aldehydes because of its high sensitivity, good reproducibility and simplicity, although 4-hydroxybenzaldehyde can also be determined by DTAN method ${ }^{8}$ with high sensitivity. Selectivity of the proposed method for aromatic aldehydes is comparable to the methods with $\mathrm{ABT}^{6}, \mathrm{DTAN}^{8}$ and $\mathrm{DDB}^{9}$, and higher than that of the method with DAN ${ }^{7}$ which gives positive results with many aliphatic aldehydes. Although the fluorophore stability of the present method is inferior to that for other methods such as ABT and DAN method, it suffices for usual measurements. If desired, the fluorescence can be stabilized by addition of acetic acid.

\section{References}

1. W. R. LaCourse and I. S. Krull, Anal. Chem., 59, 49 (1987).

2. H. T. Hoffman, Jr., J. Chromatogr., 194, 228 (1980).

3. J. J. Pisano, J. R. Crout and D. Abraham, Clin. Chim. Acta, 7, 285 (1962).

4. I. J. Holcomb, D. S. McCann and A. J. Boyle, Anal. Chem., 37, 1657 (1965).

5. C. M. McEwen and J. D. Cohen, J. Lab. Clin. Med., 62, 766 (1962).

6. T. Uno and H. Taniguchi, Bunseki Kagaku, 21, 76 (1972).

7. Y. Ohkura and K. Zaitsu, Talanta, 21, 547 (1974).

8. Y. Ohkura, K. Ohtsubo, K. Zaitsu and K. Kohashi, Anal. Chim. Acta, 99, 317 (1978).

9. M. Nakamura, M. Toda, H. Saito and Y. Ohkura, Anal. Chim. Acta, 134, 39 (1982).

10. H. Nakamura and Z. Tamura, Anal. Chem., 50, 2047 (1978).

11. P. Girgis-Takla and I. Chroneos, Analyst [London], 104, 117 (1979).

12. A. Sano, Y. Asabe, M. Suzuki and S. Takitani, Bunseki Kagaku, 32, E93 (1983).

13. A. P. Phillips, J. Org. Chem., 14, 302 (1949).

14. J. M. Bobbitt and D. A. Scola, J. Org. Chem., 25, 560 (1960).

15. P. Karrer, G. Schwarzenbach, F. Benz and U. Solmssen, Helv. Chim. Acta, 19, 811 (1936).

16. A. Dornow, Ber., 73, 78 (1940).

17. E. A. Covlson and J. I. Jones, J. Soc. Chem. Ind., 65, 169 (1946). 